QR - Issue

SOI: $1.1 /$ TAS DOI: $10.15863 /$ TAS International Scientific Journal Theoretical \& Applied Science

p-ISSN: 2308-4944 (print) e-ISSN: 2409-0085 (online)

Year: 2019 Issue: $03 \quad$ Volume: 71

Published: 05.03.2019 http://T-Science.org

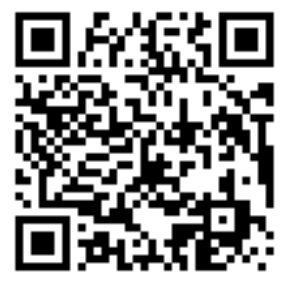

QR - Article

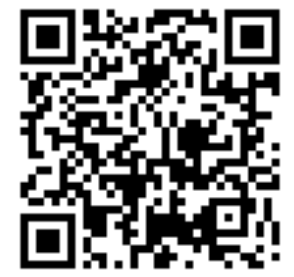

Bakhtawar Avais Dr., WMO at

Aziz Bhatti Teaching Hospital Gujrat, Pakistan bakhtawaravais20@gmail.com

Arham Hasan

Dr., Doctor in Allama Iqbal Memorial Teaching Hospital Sialkot, Pakistan arhamrockxx4@gmail.com

Fatima Aftab

Dr., Doctor in Allama Iqbal Memorial Teaching Hospital Sialkot, Pakistan fatimaaftab622@gmail.com

\title{
PHACOEMULSIFICATION RESULTING IN POSTERIOR CAPSULAR RUPTURE; A MOST COMMON COMPLICATION
}

\begin{abstract}
OBJECTIVE: This study done to determine most common complication of phacoemulsification that is rupture of posterior capsule of lens.

Study Design: it is a retrospective study.

Duration of study: In this study data was taken of previous 7 months from January 2018 to July 2018.

Setting: Study was conducted in Mayo Hospital Lahore Ophthalmology Ward Pakistan.

Patients and Methods: Total 75 cases were studied. These cases were admitted in the ward on opd bases. A Proforma was designed for documenting all data related to the patient. Proper written consent was taken from in charge of the ward for conducting this study. Data was collected from previous record of the ward. After operation all cases in study group were retained in the ward for 2-4 days. These cases were called for follow-up after one week and complications were evaluated in them. Results were calculated in the form of frequencies and data was analyzed using Microsoft office and SPSS version 2007. Data was expressed in the form of tables and graphs.

Results: There were 180 cases which underwent phacoemulsification during given period of study on elective basis. These cases were admitted and prepared for surgery after taking anesthesia fitness etc. Complete data of these cases was collected from previous record of the ward. Their operation noted and all investigations, indication of surgery and all investigations and procedure notes were seen. Out of these 180cases 75(32\%) cases developed complications related to the procedure. Posterior capsular rupture was reported in these cases due to different reasons. Most common cause of this complication was heated phacoemulsification tip in 30 cases. In 15 patients rotation of nucleus was its cause. Out of these 62 cases $6(9.7 \%)$ cases got capsular rupture during lens implantation, in 11(17.7\%) cases trauma by simco cannula, in $8(12.9 \%)$ cases capsular rupture occurred during dialing of intra ocular lens. Trauma by chopper tip occurred in 3(4.8\%) cases. It was seen that most common cause of lens rupture was heated phacoemulsification tip followed by rotation of nucleus second most common cause.

Conclusion: During phacoemulsification we should take care throughout the procedure as capsular rupture may happen in any stage of the procedure. Osmotic balance of lens and surrounding environment is most important. Heated tip of phacoemulsification is the major cause of rupure of lens.
\end{abstract}

Key words: phacoemulsification, lens rupture, posterior capsular rupture.

Language: English

Citation: Avais, B., Hasan, A., \& Aftab, F. (2019). Phacoemulsification resulting in posterior capsular rupture; A most common complication. ISJ Theoretical \& Applied Science, 03 (71), 1-4.

Soi: http://s-o-i.org/1.1/TAS-03-71-1 Doi: crossef https://dx.doi.org/10.15863/TAS.2019.03.71.1 


\begin{tabular}{|c|c|c|c|c|c|c|}
\hline \multirow{4}{*}{ Impact Factor: } & ISRA (India) & $=3.117$ & SIS (USA) & $=0.912$ & ICV (Poland) & $=6.630$ \\
\hline & ISI (Dubai, UAE & $=0.829$ & РИНЦ (Russia & $=0.156$ & PIF (India) & $=1.940$ \\
\hline & GIF (Australia) & $=0.564$ & ESJI (KZ) & $=8.716$ & IBI (India) & $=4.260$ \\
\hline & JIF & $=1.500$ & SJIF (Morocco & $=5.667$ & OAJI (USA) & $=0.350$ \\
\hline
\end{tabular}

\section{INTRODUCTION}

Phacoemulsification is a very common procedure performed for cataract in Pakistan. Cataract is very common in old age. It is formed due to senile changes. Metabolic factors are commonly responsible for this condition. Cataract is a most common ophthalmic problem among the people of Pakistan. ${ }^{1}$ Majority of cases belongs to old age. In old age metabolic changes causes opacity of lens forming cataract. Other causes include diabetes mellitus, infection etc. Young age people are least likely to acquire this problem unless in congenital acquired cataract. In this problem patient complains of gradual decrease in vision with the passage of time and on examination we see opacity in lens milky white in colour. Procedure of choice for cataract is phacoemulsification. $^{2}$ It is best procedure with best outcome but like other procedures this technique has its few complications. Most common complication related to this procedure is rupture of posterior wall of lens capsule which occurs during the procedure. It may happen in any stage of the procedure. Most common cause was heated tip of phacoemulsification which damages the capsule. Majority of cases belong to old age. ${ }^{3}$ In old age metabolic changes causes opacity of lens forming cataract. Other causes include diabetes mellitus, infection etcSo as age advances cataract incidence increases. In old age complications related to operation are also much common. Out of these 190 cases 28 patients were having co-morbidities such as diabetes mellitus, hypertension, congestive heart failure, CKD and angina pectoris making these cases a high risk group. Out of these 190 cases 62(32\%) cases developed complications related to the procedure. Posterior capsular rupture was reported in these cases due to different reasons. We should be very careful in the whole procedure regarding posterior wall of capsule. Many surgeons do this complication commonly which leads to failure of the procedure causing financial and psychological burden on the patient. Our purpose is to decrease complication rate related to this procedure. Many studies have been done previously on this topic but little data is available from Pakistan.

\section{Patients and Methods}

This is a retrospective study in which previous data of six months collected from the ophthalmology ward. Study was done in a tertiary care hospital. Total 62 cases were studied. These cases were admitted in the ward on opd bases. A Proforma was designed for documenting all data related to the patient. Proper written consent was taken from in charge of the ward for conducting this study. Data was collected from previous record of the ward. Only those cases were included in the study having complete data mentioned in the record rest of the cases with incomplete data were excluded from the study. These patients were admitted for phacoemulsification and complications were reported. Follow up of these cases was made for observing post operative outcome. Causes of capsular rupture included trauma by chopper, dialing of intra ocular lens and implantation of intra ocular lens. Usually age of patients in this study was above 50 years. There were 22 cases with age 35-45 years, 42 cases with $46-55$ years age, 63 cases having age 56-65 years, 54 cases with 66-75 years age and 19 cases were above 75 years. So as age advances cataract incidence increases. In old age complications related to operation are also much common. Most common cause was heated tip of phacoemulsification which damages the capsule. Results were calculated in the form of frequencies and data was analyzed using Microsoft office and SPSS version 2007. Data was expressed in the form of tables and graphs.

\section{Results}

There were 190 cases which underwent phacoemulsification during given period of study on elective basis. These cases were admitted and prepared for surgery after taking anesthesia fitness etc. Complete data of these cases was collected from previous record of the ward. Their operation noted and all investigations, indication of surgery and all investigations and procedure notes were seen. Out of these 190 cases 62(32\%) cases developed complications related to the procedure. Posterior capsular rupture was reported in these cases due to different reasons. Most common cause of this complication was heated phacoemulsification tip in 25 cases. There were 180 cases which underwent phacoemulsification during given period of study on elective basis. These cases were admitted and prepared for surgery after taking anesthesia fitness etc. Complete data of these cases was collected from previous record of the ward. Their operation noted and all investigations, indication of surgery and all investigations and procedure notes were seen. Out of these 180cases 75(32\%) cases developed complications related to the procedure. Posterior capsular rupture was reported in these cases due to different reasons. Most common cause of this complication was heated phacoemulsification tip in 30 cases. In 15 patients rotation of nucleus was its cause. Out of these 62 cases $6(9.7 \%)$ cases got capsular rupture during lens implantation, in $11(17.7 \%)$ cases trauma by simco cannula, in $8(12.9 \%)$ cases capsular rupture occurred during dialing of intra ocular lens. Trauma by chopper tip occurred in $3(4.8 \%)$ cases. It was seen that most common cause of lens rupture was heated phacoemulsification tip followed by rotation of nucleus second most common cause. 


\begin{tabular}{|c|c|c|c|c|c|c|}
\hline \multirow{4}{*}{ Impact Factor: } & ISRA (India) & $=3.117$ & SIS (USA) & $=0.912$ & ICV (Poland) & $=6.630$ \\
\hline & ISI (Dubai, UAE & $=0.829$ & РИНЦ (Russia) & $=0.156$ & PIF (India) & $=1.940$ \\
\hline & GIF (Australia) & $=0.564$ & ESJI $(\mathrm{KZ})$ & $=8.716$ & IBI (India) & $=4.260$ \\
\hline & JIF & $=1.500$ & SJIF (Morocco) & $=5.667$ & OAJI (USA) & $=0.350$ \\
\hline
\end{tabular}

Graph-2. Complication rate among the cases of study group.

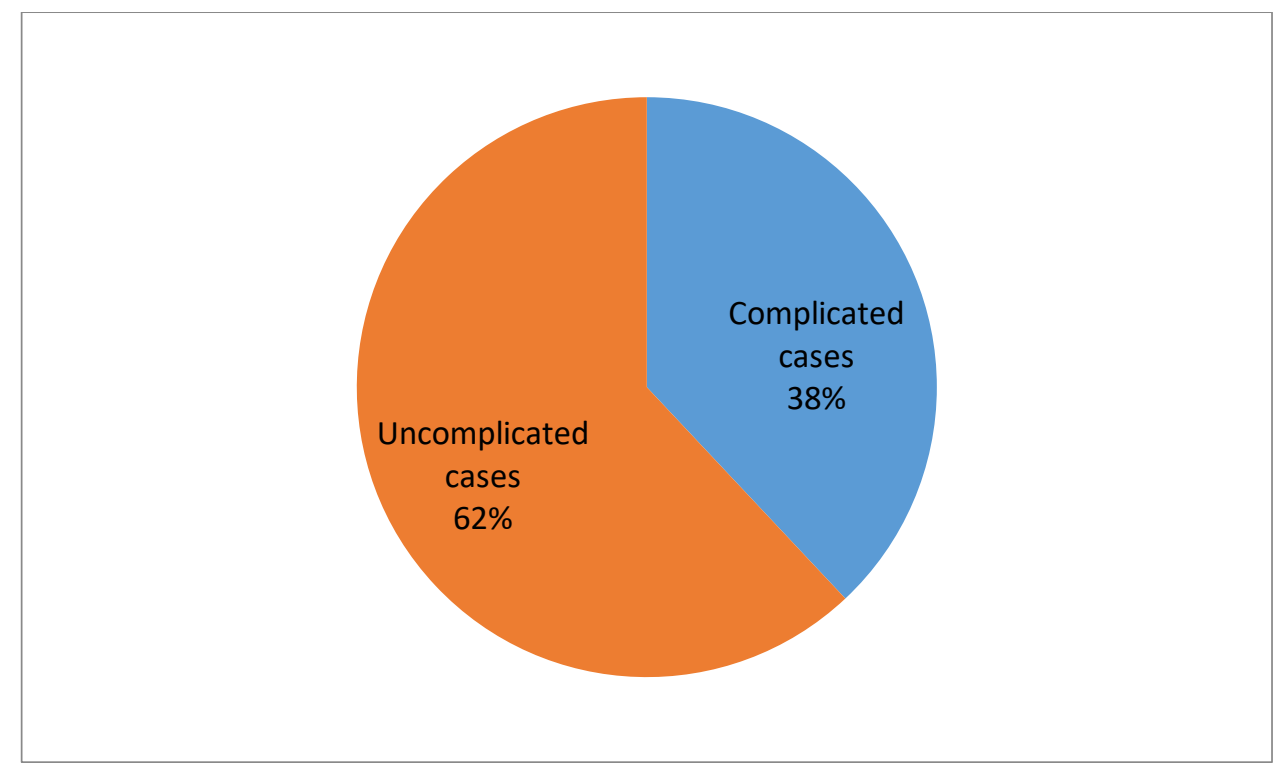

Table 1.

\begin{tabular}{|l|c|c|}
\hline \multicolumn{1}{|c|}{ Reason of capsular rupture } & Number of patients & $(\mathbf{\%})$ \\
\hline Hot tip of phacoemulsification & 30 & 40 \\
\hline Simco cannula causing trauma & 15 & 20 \\
\hline Rotation nucleus & 10 & 13.3 \\
\hline Tip of chopper causing damage & 04 & 5.3 \\
\hline Intra ocular lens dialing & 09 & 12 \\
\hline Lens implantation & 07 & 9.3 \\
\hline Total & $\mathbf{7 5}$ & $\mathbf{1 0 0}$ \\
\hline
\end{tabular}

\section{DISCUSSION}

Phacoemulsification is a procedure of choice for cataract surgery but it is associated with a most common complication of rupture of posterior capsular wall. ${ }^{5}$ Expert surgeons can avoid this complication to much extent. In this study $32 \%$ cases got this complication and rest of the cases were operated normally. In these complicated cases there were different reasons of capsular rupture. This is a retrospective study in which previous data of six months collected from the ophthalmology ward. Study was done in a tertiary care hospital. Total 62 cases were studied. These cases were admitted in the ward on opd bases. A Proforma was designed for documenting all data related to the patient. Proper written consent was taken from in charge of the ward for conducting this study. ${ }^{6}$ Data was collected from previous record of the ward. Only those cases were included in the study having complete data mentioned in the record rest of the cases with incomplete data were excluded from the study. These cases were admitted and prepared for surgery after taking anesthesia fitness etc. Complete data of these cases was collected from previous record of the ward. Their operation noted and all investigations, indication of surgery and all investigations and procedure notes were seen. Out of these 180cases $75(32 \%)$ cases developed complications related to 


\begin{tabular}{|c|c|c|c|c|c|c|}
\hline \multirow{4}{*}{ Impact Factor: } & ISRA (India) & $=3.117$ & SIS (USA) & $=0.912$ & ICV (Poland) & $=6.630$ \\
\hline & ISI (Dubai, UAE & $=0.829$ & РИНЦ (Russia & $=0.156$ & PIF (India) & $=1.940$ \\
\hline & GIF (Australia) & $=0.564$ & ESJI (KZ) & $=8.716$ & IBI (India) & $=4.260$ \\
\hline & JIF & $=1.500$ & SJIF (Morocco & $=5.667$ & OAJI (USA) & $=0.350$ \\
\hline
\end{tabular}

the procedure. Posterior capsular rupture was reported in these cases due to different reasons. Most common cause of this complication was heated phacoemulsification tip in 30 cases. In 15 patients rotation of nucleus was its cause. Out of these 62 cases $6(9.7 \%)$ cases got capsular rupture during lens implantation, in $11(17.7 \%)$ cases trauma by simco cannula, in $8(12.9 \%$ ) cases capsular rupture occurred during dialing of intra ocular lens. These patients were admitted for phacoemulsification and complications were reported. Follow up of these cases was made for observing post operative outcome. Cataract is a most common ophthalmic problem among the people of Pakistan. Majority of cases belong to old age. In old age metabolic changes causes opacity of lens forming cataract. Other causes include diabetes mellitus, infection etc. Young age people are least likely to acquire this problem unless in congenital acquired cataract. ${ }^{7}$ In this problem patient complains of gradual decrease in vision with the passage of time and on examination we see opacity in lens milky white in colour. Procedure of choice for cataract is phacoemulsification. Out of these 190 cases 28 patients were having co- morbidities such as diabetes mellitus, hypertension, congestive heart failure, CKD and angina pectoris making these cases a high risk group. Results were calculated in the form of frequencies and data was analyzed using Microsoft office and SPSS version 2007. Data was expressed in the form of tables and graphs. In various studies the rate of complication was $7-9 \%$. According to a study done by Cruz et al 9.9\% cases suffered from this complication. Another study done by Junejo and Khan reported $4.5 \%$ rate of this complication. A study done by Henning et al reported incidence of $4 \%$ in those surgeries which were done under supervision of experienced surgeons and incidence was $15 \%$ in other unsupervised surgeries. ${ }^{10}$

\section{Conclusion}

Phacoemulsification is a very commonly used procedure in our hospitals. Posterior capsular rupture is a very common complication of this procedure. Enhancing skills of surgery and supervision of scenior surgeons can reduce the incidence of this complication to much extent.

\section{References:}

1. Hashmani, S., Haider, I., \& Khan, M. A. (1997). Phacoemulsification: Results and complications during the learning curve. Pak J Ophthalmol, 13(2), 32-36.

2. Junejo, S. A., \& Khan, S. A. (1999). Phacoemulsification by stop and chop technique: Review of 200 cases. Pak J Ophthalmol, 15(4), 138-141.

3. Haider, S. A. (1999). Phacoemulsification versus conventio-nal extracapsular surgery: A study of early Astigma-tism and complication rates. Pak J Ophthalmol, 15(1), 20-23.

4. Smeets, B., Tabandeh, H., Teimory, M., \& Seward, H. (1993). Learning Phaco in a teaching environment. Bull Soc Belg Ophtalmol, 249, 23-28.

5. Hussain, M., Durrani, J., \& Nisar, A. (1996). Phacoemulsification: A review of 210 cases. Pak J Ophthalmol, 12(2), 38-43.

6. Khan, A. A., Azher, A. N., \& Chohan, A. M. (1997). Review of 100 cases of
Phacoemulsification. Pak J Ophthalmol, 13(2), 37-40.

7. Seward, H. C., Dalton, R., \& Davis, A. (1993). Phacoemusification during the learning curve: Risk/benefit analysis. Eye, 7, 164-168.

8. Curz, O. A., et al. (1992). Visual results and complications of phacoemulsification with IOL implantation performed by ophthalmology residents. Ophthalmol, 99, 448-52.

9. Hennig, A., Schroeder, B., \& Kumar, J. (2004). Learning Phacoe-mulsification. Results of different teaching methods. Indian J Ophthalmol, 52(3), 233-4.

10. Allinson, R. W., Metrikin, D. C., \& Fante, R. G. (1992). Incidence of vitreous loss by 3rd year residents performing Phacoemulsification. Ophthalmol, 99, 726730 . 